\title{
Spatial Design Makes a Difference in Student Academic Engagement Levels: A Pilot Study for Grades 9-12
}

\author{
Lennie Scott-Webber, PhD \\ INSYNC: Education Research + Design, Independent Researcher, USA \\ Roger Konyndyk, PhD \\ Statistical Consultant \& Independent Researcher, USA
}

\author{
Raechel French \\ Jason Lembke, AIA \\ Taryn Kinney AIA
}

DLR Group, K12 Educational Practice, USA

\section{doi: 10.19044/esj.2017.v13n16p5 URL:http://dx.doi.org/10.19044/esj.2017.v13n16p5}

\begin{abstract}
Our research question was, 'Can we demonstrate that the design of the built environment for grades 9-12 impacts student academic engagement levels?' A pilot study was conducted using a convenience sample, a high school (grades 9-12) in the USA's mid-west with a four-year old design solution. To answer the question we designed two online survey instruments, one for students and one for educators, enabling us to construct engagement indexes for each. We then correlated the level of self-reported engagement, as measured by our indexes, with the perceptions of the built environment. A mixed-methodology research technique was used for this research project. Focused interviews used K-12 architects $(n=6)$, administrators $(n=3)$, teachers $(n=35)$, students $(n=25)$. A fifteen (15) question 'Alpha'/pilot survey was then designed, developed, pre-tested and then submitted to the full membership of the school. Findings revealed that both students and educators agreed that the design of the built environment makes a difference relative to their engagement at both the macro (i.e., Overall) and micro (i.e., Classrooms) at a high level of significance $(\mathrm{p}<.0001)$; spatial design makes a difference. The survey proved to be both reliable and valid. Finally, we pay particular attention to questions relating to "movement" and learning.
\end{abstract}

Keywords: Engagement, design, 9-12 education, impact, EBD, learning outcomes 


\section{Introduction}

Evidence indicating the built environment impacts behavior is not new as established by classic environment behavior psychology research (Sommer, 1959, 1967; Hall, 1966). Newer work in how the built environment impacts student engagement has been studied primarily in places of higher education. The National Survey of Student Engagement (NSSE) is one prominent research group working on this research for some years. Their methodology "...relies on self-reports. Using self-reports from students to assess the quality of undergraduate education is common practice. Some outcomes of interest cannot be measured by achievement tests, such as attitudes and values or gains in social and practical competence. For many indicators of educational practice...student reports are often the only meaningful source of data” (Kuh, 2002, p.3).

The innovation of this research study begins with the research question in an 'Alpha', or pilot search to understand if students and educators in grades 9-12 (high school as determined in the USA) perceive an impact of the design of the built environment at the macro (Overall building) and micro (Classroom) levels on their academic levels of engagement using a self-reporting technique. New survey instruments, one each for students and educators, were generated to address the research question with the goal to build a reliable and valid instrument for future use. The research question asked, "Can we demonstrate that the design of the built environment for grades 9-12 impact student academic engagement levels?”

Why look at student engagement? It is a high predictor of student success academically, socially, emotionally and behaviorally (Fursman 2012; Cuseo, n.d.; NSSE, 2013).

\section{Purpose and Sample}

We needed to systematically design and develop survey instruments that (1) are both reliable and valid, (2) generate Engagement Indexes for both students and educators, respectively, and (3) answer the research question. We considered educator engagement as well as student engagement, as evidence suggests that when the educators are more engaged in their work the students will be more engaged in theirs. The convenience sample was one high school with grades 9-12 in the central region of the USA with a four-year-old design solution using students and educators as respondents. The method used self-reporting (Brener, Billy \& Grady, 2003) perceptions of impact on engagement levels. 


\section{Developing the “Alpha”/Pilot Instruments}

Two steps were involved in the development of these instruments. The first step included: (a) focused interview sessions held with K-12 architects ( $n=6)$; (b) onsite focused interview sessions with two groups of students $(n=25)$, two groups of educators $(n=35)$, and one group of administrators $(\mathrm{n}=3)$; (c) data were transcribed, translated, synthesized, patterns analyzed, and embedded into the questionnaires; and (d) an online survey, our Alpha with 15 question groups was designed and developed to address the research question.

In step two, the online survey was reviewed, edited and pre-tested with the K-12 research team and then submitted to the sample, resulting in 252 usable student surveys, of which 102 could be used to correlate engagement against other variables, and 77 usable educator surveys. Data were prepared and then analyzed employing multiple statistical techniques correlation coefficients, simple linear regression, t-test, Wilcoxon signed rank test, multiple regression, principal component analysis, factor analysis, cluster analysis, contingency table analysis, and Cronbach's alpha. Finally, data were synthesized and findings reported. Multiple statistical techniques are important to use in the first iteration of a survey instrument to ensure validity and reliability.

\section{Data Preparation}

Survature software was used to collect the online responses. Respondents could use a cell phone, tablet, or Personal Computer (PC) to respond to the survey. The responses were then transferred to an Excel spreadsheet, which in turn was read into JMP statistical software used for the analysis of the survey and production of the graphics. Respondents who used a PC were significantly more likely to complete the survey than those using a cell phone. "Survey fatigue" was a problem with the students, as about $48 \%$ of those who began the survey did not finish it. On the other hand, only about $14 \%$ of the teachers dropped out part-way through the survey.

\section{Reliability and Validity}

Both survey instruments proved to be reliable and valid. Questions 1 and 2 provided a 'control' for how both students and educators view the teaching practices and where these classes were taught, which turned out to be mostly lecture and almost always in a classroom throughout the academic day. All the other question groups on the teacher survey had Cronbach's alpha greater than .7. On the student survey only one question group had alpha smaller than .7, and that value was .676, so Cronbach's alpha indicates very good reliability overall for both surveys. 
Generally, responses also show consistency. On both surveys, questions in which respondents evaluated their physical environment, all correlate well with the respective engagement indexes, indicating convergent validity. Further evidence of convergent validity is the great similarity of the patterns of answers on the two surveys. On both surveys, questions, which dealt with the importance of items in the abstract have a much lower and weaker correlation with the respective engagement indexes, an indication of discriminant validity. Similarly, individual items that have opposite desirability from the other items in a question ("Crowded" and "Distracting" and the tiredness and "Can't wait to go home" items) have negative correlations with the other items in the question group on the two surveys. Thus, we have significant evidence that the survey instrument is both reliable and valid, fulfilling purpose \#1.

\section{Generating Engagement Indexes}

On the student survey, question 9 (How engaged academically are you?) showed a rather skewed distribution and little differentiation, and so that question by itself did not prove to provide a good measure of student engagement. However, question 14 in both surveys, (educators and students) which asked how one felt at the end of the day, included several indicators of engagement, e.g., "Stimulated by what I am learning/teaching," "Made good use of my time," and so on. Based on both a principal components analysis and factor analysis for questions in 9 and in 14 taken together from the student survey; a good 'Student Engagement Index' is the sum of the “negative” items 'mentally tired, 'can't wait to leave,' and 'physically tired' subtracted from the sum of all the other items, which were "positive."

Question 9 on the teacher survey asked about students rather than teachers, and so our "Educator Engagement Index" omits question 9 from the educator survey, but is otherwise the same as that for the students. Thus, we have engagement indexes for students and educators, satisfying purpose \#2.

\section{Analysis of the Surveys}

This survey was segmented into three separate areas: (1) understanding the OVERALL perceptions of the design of the built environment, the macro level, (2) the perceptions of the CLASSROOM, the micro level, and (3) DEMOGRAPHICS. Demographic factors on the survey had no impact on the findings and will not be discussed further. On both surveys the first question asked about the amount of lecturing versus other teaching practices, and the second asked where teaching took place. We wanted to know whether educators were using building features designed to facilitate other teaching methods, which it is believed should promote student engagement. Some of these building features beyond the classroom 
included 'breakout/ collaborative' spaces, open cafeteria/meeting areas, and the ability to move out of doors. Responses showed the dominant practice as perceived by both the students and the educators was that of lecture mode, conducted primarily in the classroom.

\section{The Macro Level - The Building "Overall”}

The first questions asked about perceptions of the building overall. We now highlight some questions as they related to engagement, as article space limitations prevent an analysis of each question. Each questions had multiple items; in general, we created composite scores for each question simply by adding the responses to individual items together. Principal components analysis and factor analysis were used to guide the construction of the composite scores (see Figure 1). Question 3: Please rate your school's OVERALL physical environment relative to these attributes...

Figure 1. Question 3 vs. Engagement Indexes.

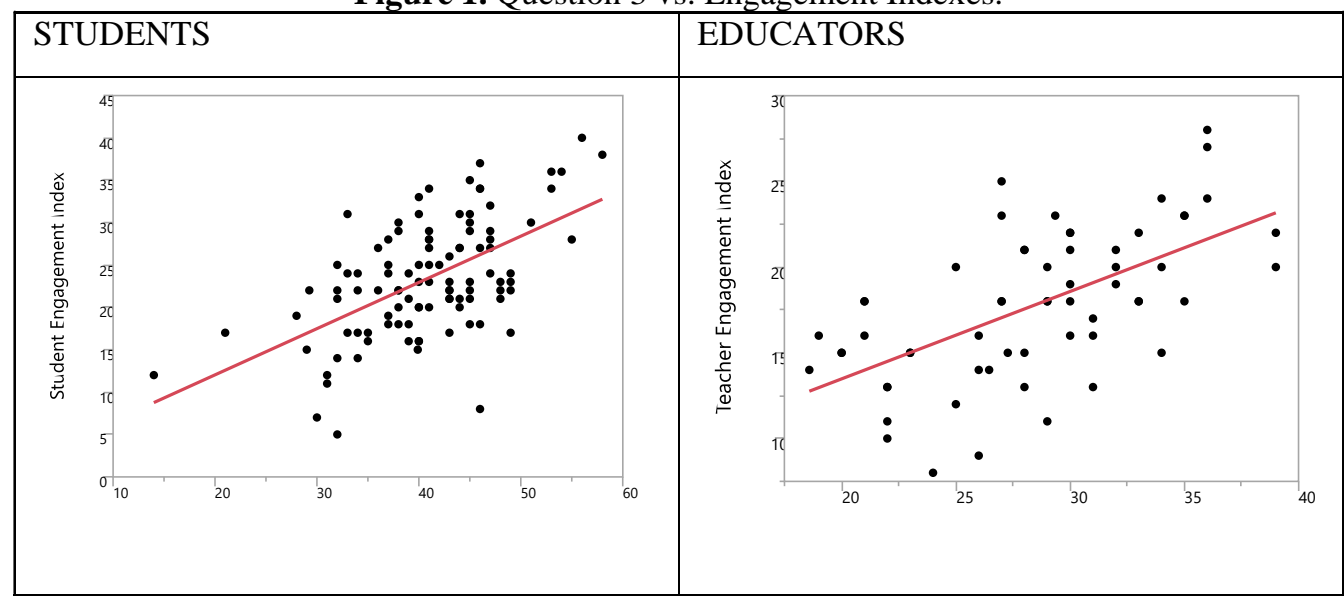

The $\mathrm{X}$-axes here are the sum of the ratings of noise level, lighting level, etc., and the $\mathrm{Y}$-axes represent the respective engagement indexes. Regressing the engagement indexes on the composite scores for question 3 gives $\mathrm{R}^{2}=.32$ for the students and .36 for the educators, with $\mathrm{p}<.0001$ for both. Thus, we concluded that the greater the overall satisfaction with the physical environment, the higher the level of engagement, for both students and educators (see Figure 1).

Question 6: Tell us how well your school's physical design impacts your ability to...?, with specific items including access to peers, engaging in classroom activities, learning effectively, and so on. Regression of the engagement indexes on the composite scores showed that the more positive impact the respondents see from the physical design, the higher the level of engagement for both students and educators (see Figure 2). Here we have $\mathrm{R}^{2}$ $=.25$ for the students and .37 for the educators, with $\mathrm{p}<.0001$ for both. 
Figure 2. Question 6 vs. Engagement Indexes.

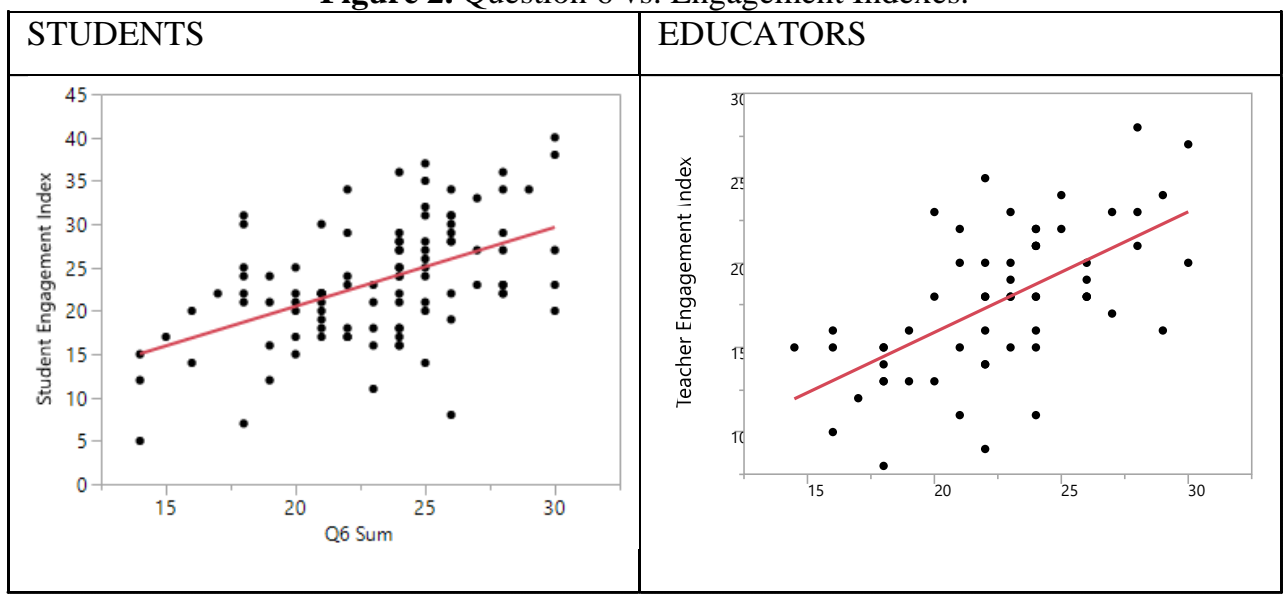

Question 8 directly asked, How does the OVERALL design of the physical environment impact your ability to...: a willingness to work for higher grades, perception that you can stay connected to the school community, a motivation to keep up with assignments, an ability to move around to be deeply engaged in one's learning, a perception that learning is valued, an ability to do one's best work, and the motivation to attend classes. All responses ranged from the ' $3=$ 'to some degree' to $4=$ 'very much so' range so by both constituents, indicating that both groups perceive an impact from the physical environment on learning. The educators' perceived that the impact of the physical environment on their ability to get students to move to become deeply engaged was considerable, with their answers averaging 4.08 on a 5-point scale.

Further, a statistical analysis of question 8 by itself shows that both students and educators see a real effect, with statistical significance, of the physical environment on their engagement in their learning/teaching. Figures 3a and 3b, below, give the means of the responses to the individual question items for the two groups regarding Question 8.

Figure 3a. (Q8 Students) Impact of physical environment on...

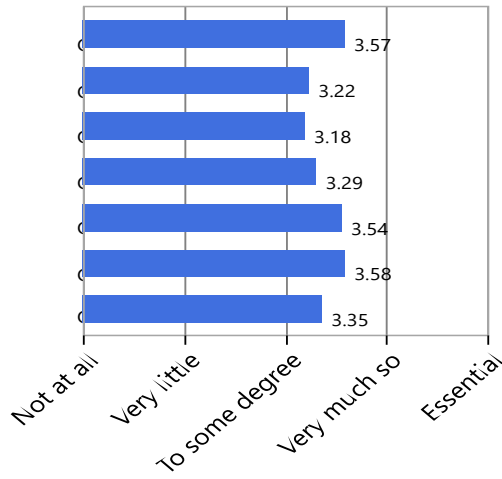


Figure 3b. (Q8 Educators) Impact of physical environment on...

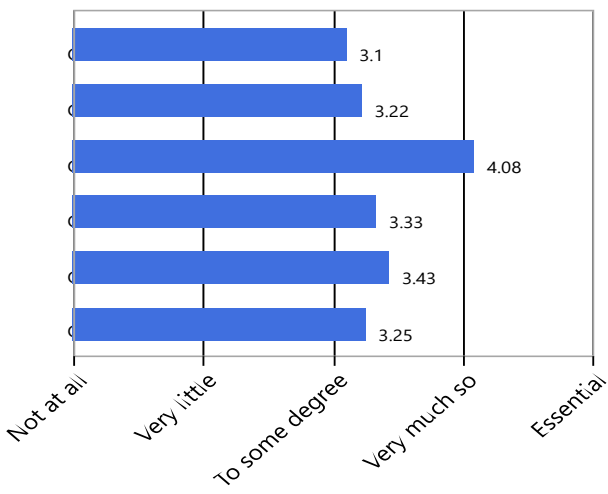

\section{Classroom - The Micro Level}

CLASSROOM questions addressing the microenvironment were next. For our purposes, the most interesting question about the classroom was question 10: Now, just think about your school's classrooms, how well do they provide you with the ability to... Items rated included seeing materials presented, hearing others, moving around to stay engaged, access to technologies, etc. (see Figure 4).

Figure 4. Question 10 vs. Engagement Indexes.

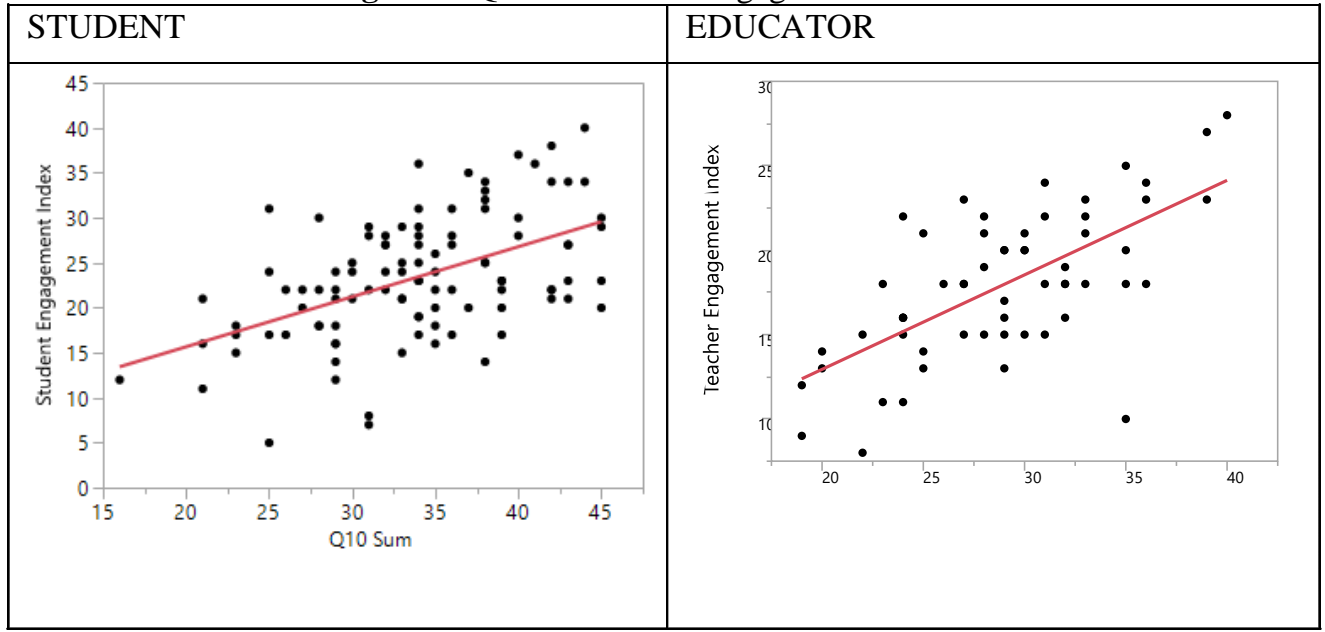

As figure 4 shows, the more each group sees the classrooms as functioning well, the higher their level of engagement tends to be. Regressions here yielded $\mathrm{R}^{2}=.26$ for the students and .43 for the educators, with $\mathrm{p}<.0001$ for each. Note that educator engagement is very strongly related to satisfaction with the classroom.

Therefore, we have strong evidence that the design of the building is correlated with both student academic engagement and teacher engagement, fulfilling purpose \#3. 


\section{Student Engagement and Hands-on Learning}

An item in Question 1 on the student survey, the frequency of 'handson-learning' shows a clear correlation with the student engagement index. Regressing the student engagement index on the frequency of hands-on learning yielded a p-value of .006, showing that more frequent hands-on learning tends to be associated with higher student engagement (see Figure 5).

Figure 5: Bivariate Fit of Student Engagement Index (vertical axis) versus Q1f Hands-on Learning (horizontal axis).

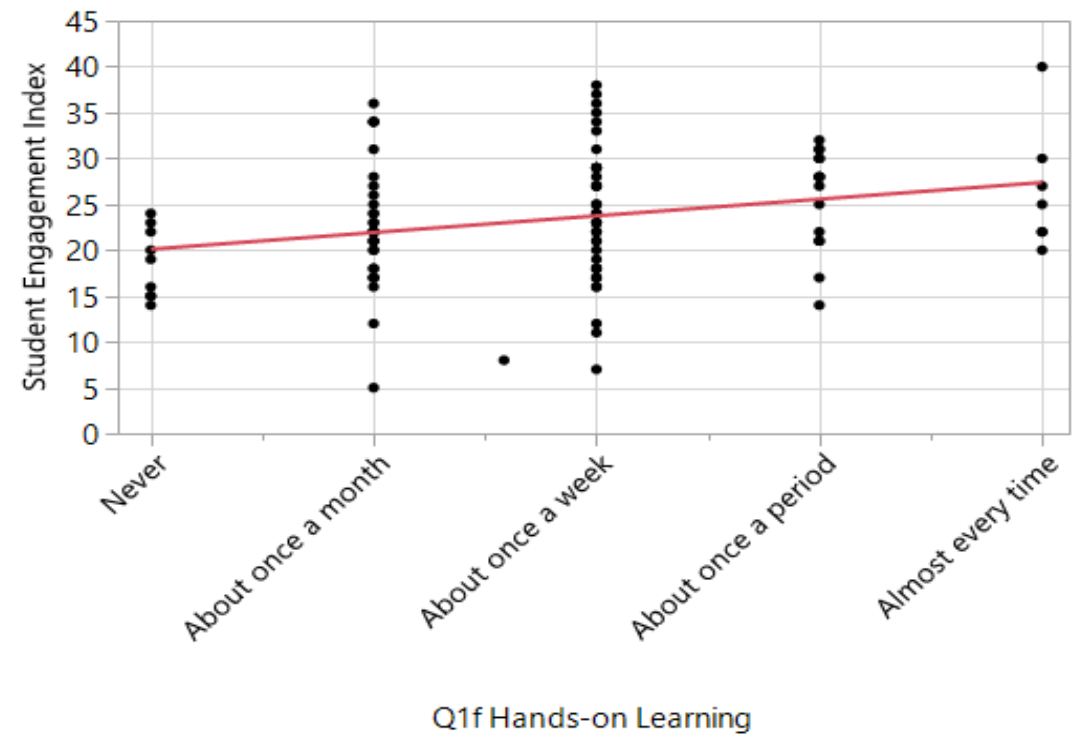

\section{Summary - Cluster Analysis:}

Clustering is a statistical technique that does involve some judgment calls, such as the number of clusters to retain, the exact clustering algorithm to use, and so on. We present cluster analyses of both students and educators as a useful summary of our findings, by giving a broad-brush picture of each group at various levels of engagement. We begin with the students (see Figure 6) describing the clusters from the most engaged to the least engaged. 
Figure 6. Cluster analysis of student engagement, showing the relative means on several measures for each cluster. Following the lines on the chart allows us to characterize each group.

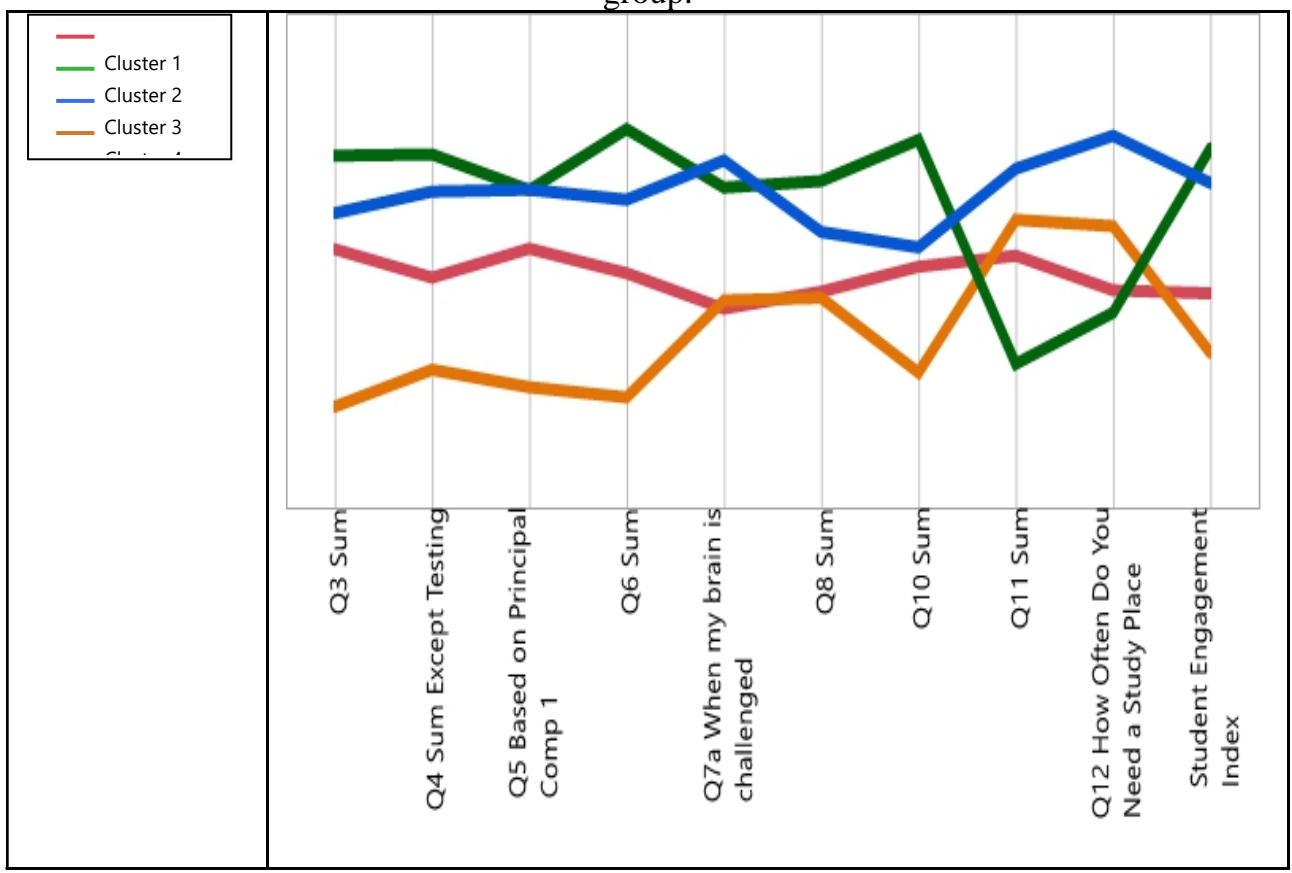

Cluster 2 (green): The most engaged, who are happy with the overall building (Q3), want to be challenged (Q7a), happy with their classrooms (Q10), do not see many design issues to address (Q11), don't need a study place outside of class (Q12); similarly Cluster 3 (blue): Very engaged, high on seeing influences of the environment, want to be challenged, but have some design issues to address (Q11), and need a study place outside of class. Compare these to Cluster 1 (red): Not so engaged, middle-of-the-road or low on everything; and Cluster 4 (orange): Least engaged, unhappy with the overall building (Q3), very low on seeing influences of the environment on their engagement, not happy with their classrooms (Q10), have some design issues to address (Q11).

As with the students, a cluster analysis of the composite variables used to analyze the impacts on educator engagement provides a good summary of the findings (see Figure 7). We explain these again from the most engaged to the least. 
Figure 7. Cluster Analysis of Educators: Relative means of the clusters for various questions.

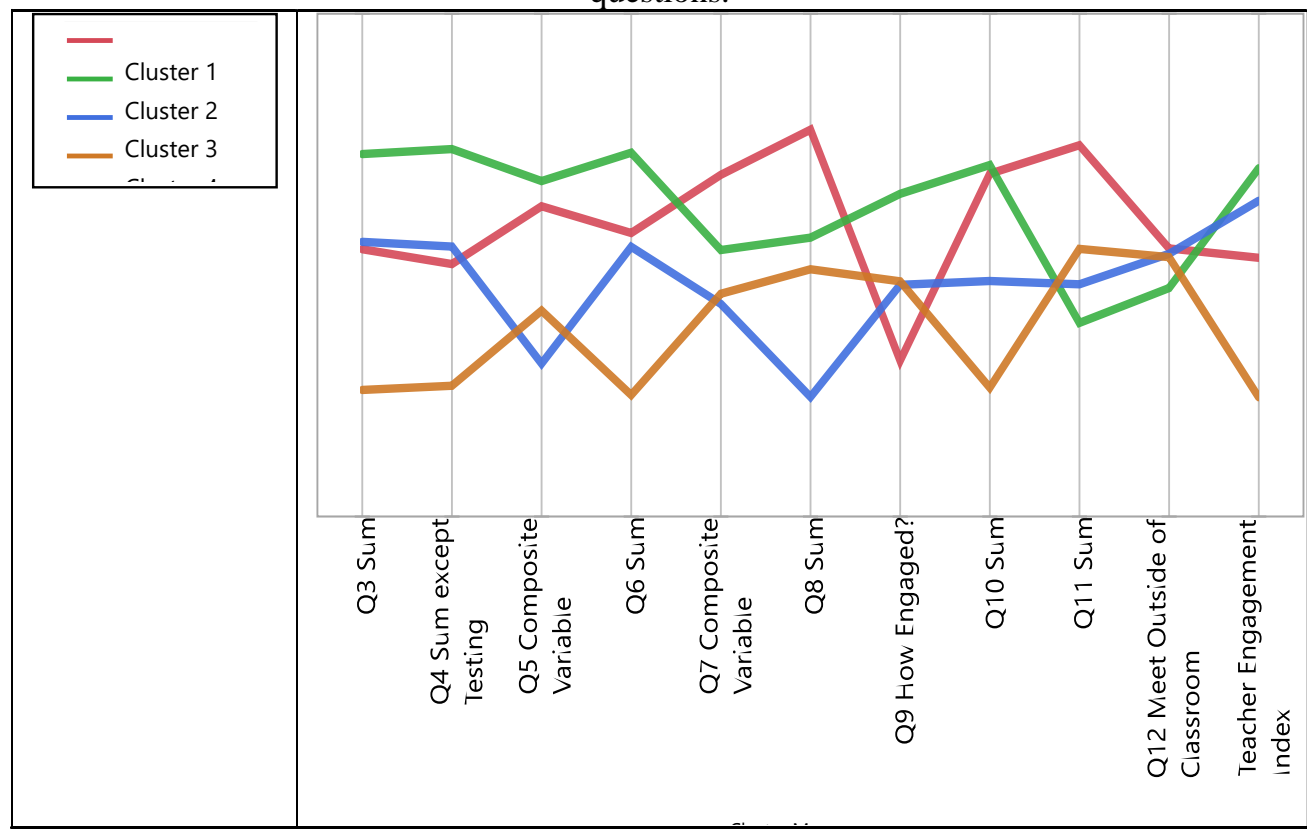

The contrast between the clusters of the most engaged educators and the least engaged is revealing, and quite similar to that of the students:

Cluster 2 (Green): For the most engaged educators, they: give the most favorable ratings of the school's physical environment (Q3), see the school district placing the highest values on the items in Q4 (Creativity, Mentoring, etc.), place the highest desirability on the items in Q5 (Stimulating, Flexibility, etc.); have the most positive view of how well the school's physical design impacts their ability to access peers, have students engaged, etc. (Q6); see their students as being the most engaged (Q9); have the most positive view of how well the classrooms facilitate their work (Q10) and the least need to have design issues addressed (Q11);

In contrast, look at the means for cluster 4 (Orange), the least engaged educators. They: give the least favorable ratings of the school's physical environment (Q3); see the school district the lowest values on the items in Q4 (Creativity, Mentoring, etc.); are near the bottom on the desirability on the items in Q5 (Stimulating, Flexibility, etc.); have the most negative view of how well the school's physical design impacts their ability to access peers, have students engaged, etc. (Q6); give ratings near the bottom to the items in Q7 as to helpfulness for students to become engaged; and have the least positive view of how well the classrooms facilitate their work (Q10). 


\section{Addendum: Moving to Learn}

Finally, we report some unexpected findings, which we have titled 'moving to learn.' High levels of 'moving to learn' equated to high levels of student engagement from both the educators' and students' perspectives and prompted us to share these unexpected findings.

\section{Educators}

We looked at the correlations of several questions that seem to relate to movement and learning. Based on correlation coefficients significantly different from zero at the $\mathrm{p}=.05$ level, we conclude the following:

- 'Lecture' is negatively correlated with all the other variables we considered here. The more frequently an educator lectures the...

o Less frequently the teacher uses hands-on learning;

o Less important the teacher thinks it is to be able to move about to learn;

o Less the teacher sees the physical environment impacting his/her ability to move around to get students deeply engaged $(\mathrm{p}=.0506)$; and

o Less the teacher sees the classroom providing the ability to move around to keep students engaged.

On the other hand, educators who see the design of the classroom as providing them with the ability to move around to keep students engaged... Tend to lecture less often;

- Are more likely to believe that the school's design shows that the school values hands-on work;

- Tend to assign higher importance to being able to move about to learn for the students to be engaged;

- Tend to see more impact of the physical environment on their ability to move to get students deeply engaged; and

- Are less likely to believe that inability to move to learn as needed is a design issue to be addressed (see Figure 11).

\section{Students}

Results for the students were basically similar, though not identical. 'Lecture' was correlated with only one of the other variables considered. Students who experience more lecturing...feel less impact from the environment on their ability to move around to be deeply engaged in their learning.

Alternatively, students who believe that the design of the physical environment impacts their ability to move around to be deeply engaged in their learning: say that they experience less lecturing, are more likely to believe that experiencing hands-on learning is important for them to become 
actively engaged in their learning, and are more likely to believe that the ability to move about to learn is important to help them become actively engaged in their learning.

Students who believe that experiencing hands-on learning is important for them to become actively engaged in their learning are also more likely to believe that the ability to move about to learn is important to help them become actively engaged in their learning, and they are more likely to believe that the design of the physical environment impacts their ability to move around to be deeply engaged in their learning.

Students who say that their classroom provides them with the ability to move around to stay engaged...tend to experience more hands-on learning; are more likely to believe that their school district values hands-on work; are less likely to believe that inability to move to learn as needed is a design issue that needs to be addressed.

Overall, the correlations show consistency, further evidence of convergent validity. In figure 10 below, comparing Q7g Can move about to learn vs. Q7c Experience hands-on learning, one can see on the left side of the chart a trajectory indicating the more a student perceives he/she can move about to learn from 'helpful', to 'very helpful' to 'critical' for their learning, mirrors their perception of experiencing hands-on learning as a contributing factor for their learning. For Q7g Importance of Can move about to learn vs. Q8d Impact of Physical Environment on Ability to move around to be deeply engaged in my learning the chart on the right of figure 10 illustrates that students perceive 'somewhat helpful' to 'very helpful', it also shows a perception that perhaps the design of the environment (i.e., CLASSROOM) is not designed to support this need well. In figure 8 below, the size of the dots indicates the number of responses.

Figure 8. Movement Charts re: Students.

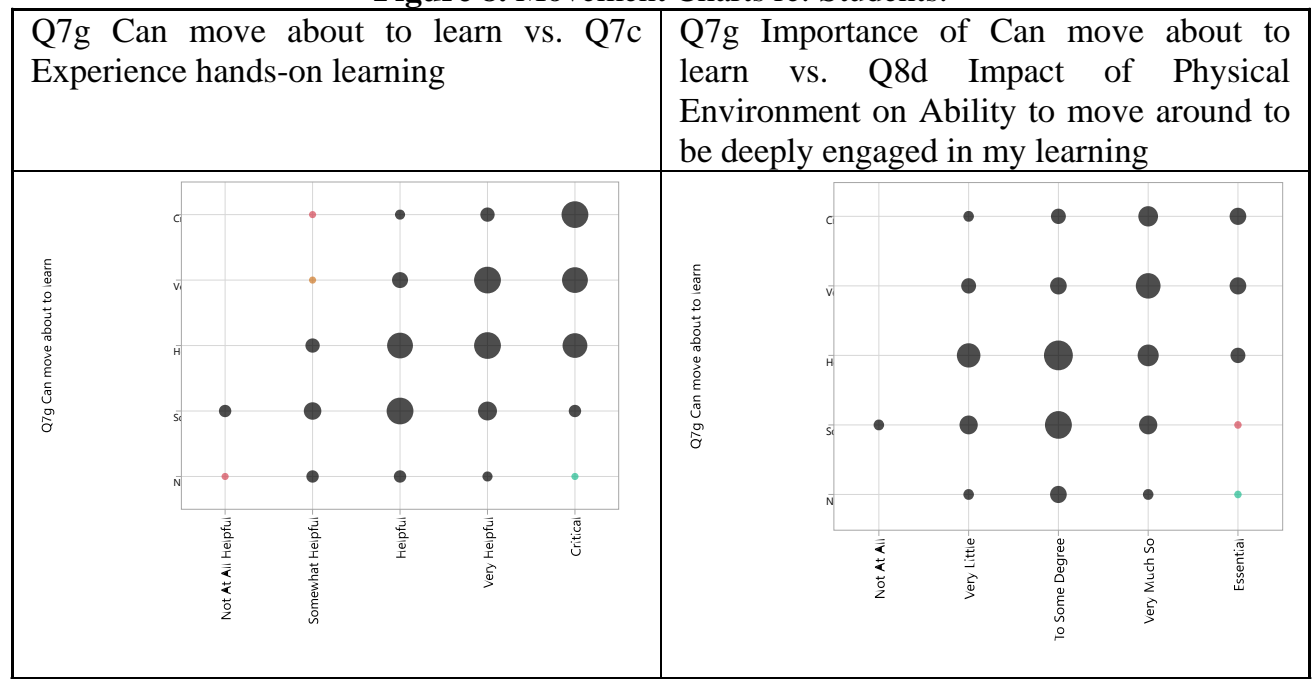


This concludes the description of the findings. The research project's Phase I had two steps. Step one addressed the multiple constituent interviews, and step two was the development of actual Alpha survey tool and the analysis of the data generated with it.

\section{Limitations and Conclusions}

\section{Limitations}

We used a convenience sample from only one school with grades 912 respondents including educators and students. Therefore, one cannot generalize or extrapolate the findings to other schools. However, additional survey work is ongoing to increase sample size, aggregate results and correlate them. For the students, 'survey fatigue' was an issue, and therefore the level of non-response could bias the results. While a survey cannot directly measure the impact of a factor on engagement, our work does demonstrate that satisfaction with the built environment is clearly correlated with a deep level of engagement, from both students and educators perspectives.

\section{Conclusion}

We have developed a survey instrument that (1) is both reliable and valid, (2) generates a Student Engagement Index, and (3) answers the research question (Can we demonstrate that the design of the built environment for grades 9-12 impact student academic engagement levels?). Building on the knowledge garnered in the Alpha phase, the next phase (Beta) will attempt to generate an even more robust and scalable instrument by studying multiple schools and then aggregating that data.

This study looked at the built environment at two levels, a macro (i.e., OVERALL) and a micro (i.e., CLASSROOM). In the questions addressing the design of the OVERALL environment, the self-reporting perceptions from both constituents indicated that both students and educators concur that it (i.e., the design of the built environment) in fact makes a difference at a statistically significant level. The better the ratings of their school's physical attributes, the higher the level of student engagement was perceived $(\mathrm{p}<.001)$. When asked a series of questions related to the CLASSROOM experiences, this area also received positive perceptions from both respondent sectors. The more the students saw their classrooms as providing for their needs, and the physical aspects desirable, the higher their level of engagement $(p<.001)$. Respondents see a real effect of the physical environment on their engagement in their teaching and learning $(p<.0001)$.

Findings suggested that lecturing less, using hands-on pedagogical practices, and moving to learn are all key to both students and educators in terms of student academic engagement. To accommodate these pedagogical 
and learning practices the design of the built environment must address these functional needs at both the macro and micro levels. Although the findings represent one convenience sample, we believe that the strong statistical findings suggest that designing curriculum, pedagogical practices, and spaces to provide a needed flexibility appears critical to students' success, and being deeply engaged in their learning process. The bottom line - the design of space matters when working to achieve a deep level of student academic engagement.

\section{References:}

1. Abell, N., Springer, D. W. \& Kamata, A. (2009). Developing and validating rapid assessment instruments. Oxford University Press.

2. Brener, N. D., Billy, J.O.G., and Grady, W.R. (2003). Validity of selfreported survey data; Assessment of factors affecting the validity of self-reported health-risk behavior among adolescents: evidence from the scientific literature [pdf 200K]. Journal of Adolescent Health, 33:436-457.

From: https://www.minnetonkaschools.org/uploaded/Documents/Dist/Tonka_ Cares/Reveal_What\%27s_Real/Validity_of_Self_Report.pdf

3. Cuseo, J. (n.d.). Student Success: Definition, Outcomes, Principles and Practices. E-source for college transitions. SC: National Resource Center for the First-Year Experience \& Students in Transition, University of South Carolina. Retrieved February 21, 2017 from: https://www2.indstate.edu/studentsuccess/pdf/Defining\%20Student $\% 2$ 0Success.pdf

4. Fursman, P. M. (2012-Thesis). The national survey of student engagement as a predictor of academic success. Theses, Dissertations, and Other Capstone Projects. Paper 155. MN: Cornerstone. Minnesota State University, Mankato.

5. Gorsuch. R. L. (1983). Factor analysis ( ${ }^{\text {nd }}$ Ed.). Hillsdale: Erlbaum.

6. Hall, E. T. 1966. The Hidden Dimension. Garden City, NY: Doubleday Press.

7. Kuh, G. (2002). The National Survey of Student Engagement: Conceptual Framework and Overview of Psychometric Properties. IN: Indiana University Center for Postsecondary Research and Planning.

8. National Survey of Student Engagement. (2013). A Fresh Look at Student Engagement-Annual Results 2013. Bloomington, IN: Indiana University Center for Postsecondary Research.

9. Sommer, R. (1959). Studies in personal space. Sociometry 22:247-60.

10. Sommer, R. (1967). Small group ecology. Psychological Bulletin 67(2):145-50. 